\title{
The development of performance and cost indicators for preschool immunisation
}

\author{
E ALBERMAN, E WATSON, P MITCHELL, AND S DAY \\ Department of Clinical Epidemiology, The London Hospital Medical College
}

SUMmARY The organisation, premises, and staffing of three child health clinics of different types in an inner city area have been studied and related to information on immunisation derived from their computerised child register and other returns, together with some simple estimates of cost.

Differences were found between overall uptake of different antigens, consent rate, compliance after consent had been given, and the median age at immunisation for children allocated to each clinic. Thus consent to pertussis immunisation varied from $90 \%$ in one clinic to $69 \%$ in the other two. In the clinic with the high consent rate, however, only $66 \%$ of those whose parents had consented actually received all three doses compared with $82 \%$ and $85 \%$ in the other clinics. The median age of immunisation also showed pronounced differences between the clinics-314, 351, and 375 days, respectively, for the third dose of the triple course.

There were differences in characteristics of the clientele served by each clinic and in staffing and facilities, which led to differences in costs, as well as contributing towards the variable patterns of uptake.

We suggest that indicators such as these, largely available from the child health computer system, are used systematically to identify ways of improving uptake and increasing cost effectiveness.

There is at present a renewed interest in the organisation, effectiveness, and cost of child health services and a need for the further development of indicators of their performance. ${ }^{1}$

A small but intensive study has been carried out, looking into the organisation, premises, and staffing of three child health clinics of different types in an inner city area, relating this to information derived from their computerised child registers, immunisation records, and work activity returns together with some simple estimates of cost. The results are described in the following account, which is designed to be an example of methods that may be used in the development of improved performance indicators.

\section{Methods}

Three out of a total of 16 child health clinics in the district, all using the same computerised child health system, were chosen for study, largely because of their contrasting characteristics.

Members of the research team attended numerous clinic sessions and were allowed access to staffing figures, other cost estimates, and returns relating to immunisations and other activities. The data on immunisation activity were obtained in two ways. One researcher carried out a manual analysis of recorded immunisations given in the three clinics over the previous three years. For children born in one calendar year (1982), these records were checked against the computer listing generated by the clinic returns to the Child Health Section of the Regional Computer Centre, who use the National Child Health System Registration and Immunisation Modules. $^{2}$ There proved to be virtually perfect agreement between these data.

Costing data relating to the relevant clinic sessions were obtained from the district treasurer, and data relating to the pharmacy cost of the materials required for immunisation were obtained from the district pharmacist's office.

The denominator populations used in the analyses of uptake and consent were those of the number of children aged under 5 years of parents resident in the district as at 28 June 1984 , who were allocated by the district clerical staff to one of the three clinics. In the district concerned the allocation is normally 
geographically based, except for patients of those general practitioners running their own child health clinics. The parents are consulted about this allocation, which is made shortly after birth, except where children have subsequently moved into the district. They may be reallocated to a different clinic if they wish. There is, however, no compulsion on the parents to restrict their visits only to the clinic to which they are formally allocated.

\section{Results}

\section{The clinics.}

\section{General practitioner $(G P)$ clinic}

This clinic is run by a group general practice for their own patients who nearly all choose to be allocated to this clinic for their babies' immunisations. The practice is sited in an attractive building that has been renovated to act as a health centre. There is a high quality of furnishing, carpeting, and decoration, and the premises are exceptionally well kept.

\section{Health centre}

This is in a different wing of the same premises as the GP clinic but run by the District Health Authority with their own staff. The quality of the premises is as described above. The allocation of families to attend this clinic is largely geographical. The catchment area is one with a high proportion of new immigrants (Table 1), many of whom had previously been attending an older clinic that is still functioning.

Table 1 Allocated case load of children aged under 5 in study clinics as of 28 June 1984

\begin{tabular}{|c|c|c|c|}
\hline & \multicolumn{3}{|l|}{ Clinic } \\
\hline & $G P$ & Health centre & Child health \\
\hline \multicolumn{4}{|l|}{ No of children under 5} \\
\hline $\begin{array}{l}\text { No of families to which } \\
\text { these belong }\end{array}$ & $6(0) 0^{*}$ & $670^{*}$ & $7(0)^{*}$ \\
\hline $\begin{array}{l}\text { Average No of children } \\
\text { under } 5 \text { per family }\end{array}$ & $1 \cdot 3^{*}$ & $1 \cdot 5^{*}$ & $1 \cdot 3^{*}$ \\
\hline \multicolumn{4}{|c|}{$\%$ Ethnic group (1982 births only): } \\
\hline White & 67 & 19 & 49 \\
\hline Asian & 9 & 61 & 20 \\
\hline Other & 11 & 5 & 10 \\
\hline Not known & 13 & 16 & 21 \\
\hline All & 100 & $1(1)$ & 100 \\
\hline \multicolumn{4}{|c|}{$\%$ Moved into district ( 1982 births only): } \\
\hline Resident at birth & 93 & 84 & 79 \\
\hline $\begin{array}{l}\text { Moved into district } \\
\text { after birth }\end{array}$ & 7 & 16 & 21 \\
\hline All as at June 1984 & $1(x)$ & 100 & 100 \\
\hline
\end{tabular}

${ }^{*}$ Derived from health visitor records; otherwise derived from child health computer records.
Child health clinic

This District Health Authority clinic is in modern, but somewhat vandalised, premises attached to local authority flats. Although spacious, the quality of the premises, furnishings, and decoration is inferior to that of the other two clinics. The allocation of families is geographically based. the catchment area approximating to the ward boundary. The clients mainly live in high rise flats or maisonettes within easy walking distance.

Characteristics of the clients allocated to the clinics.

Table 1 gives the numbers and characteristics of the clients allocated to the clinics, and shows clearly the major difference between them, clients allocated to the GP clinic being predominantly white and to the health centre predominantly Asian, largely Bangladeshi. The ethnic group constitution of the third clinic lies somewhere between the other two. The higher mean family size characteristic of the Asians in this country is also reflected in these statistics and was very evident to the researchers who observed the effect of the simultaneous attendance of many families with large numbers of preschool children in the clinic sessions in a fairly small waiting area.

It was made clear to the researchers that over and above the differences in ethnic distribution the clients of the GP clinic tended to be the most determined and articulate parents, somewhat in contrast to even those indigenous clients of the other two clinics. Table 1 also shows the relative stability of residence of the clients of the GP clinic compared with the high proportion of 'movement in' by clients in the other clinics.

Staffing in the clinics. Table 2 gives the numbers of different staff allocated to these clinics in 1984 and relates these to the number of children aged under 5 allocated to each clinic. It is clearly invidious to

Table 2 Average number of staff per clinic session as in 1984

\begin{tabular}{lccc}
\hline & \multicolumn{1}{l}{ Clinic } & & \\
\cline { 2 - 4 } & $G P$ & Health centre & Child health \\
\hline $\begin{array}{l}\text { Clinical medical officer/GP } \\
\text { Health visitor }\end{array}$ & 2 & 2 & $1 \cdot 5$ \\
$\begin{array}{l}\text { Clerical officer } \\
\text { Auxiliary help }\end{array}$ & $1 \cdot 5$ & 3 & $2 \cdot 5$ \\
$\begin{array}{l}\text { Interpreters } \\
\text { No of children aged under }\end{array}$ & 1 & $0 \cdot 5$ & 1 \\
5 allocated & 753 & 1 & $0 \cdot 5$ \\
No of allocated children & & 999 & 0 \\
for each: & & & 873 \\
Medical staff & 377 & 500 & \\
Health visitor staff & 502 & 333 & 582 \\
Other staff & 502 & 285 & 349 \\
\hline
\end{tabular}


draw general conclusions from such small samples, but the trend suggests, as one might expect, that the ratio of allocated medical staff to children is highest in the GP clinic and health visitors to allocated children highest in the health authority clinics.

Performance in respect to immunisation uptake. Several different measures have been used as an indicator of performance in respect to uptake of immunisation. Only one year's cohort of births (1982) has been studied in detail in respect to these questions, and the situation described is as it was in June 1984.

The indicators we have looked at comprise: (a) consent to any part of the triple course; (b) consent to all parts of the triple course, including pertussis immunisation; (c) consent to measles immunisation; (d) the proportions who had actually received the first and third doses of the primary course, a third dose of pertussis immunisation, and measles immunisation by June 1984; (e) the proportion who received them in the clinic to which they were allocated; and (f) the median age at which these were received. Clearly, we could have used indicators applying to any of the doses in the full programme of immunisation, but here we have presented only those considered the most important.

Table 3 summarises the findings in respect to these 'indicators'. These show pronounced differences between the clinics in the proportions of parents consenting to different immunisations, in the actual uptake in those babies whose parents had consented, and the ages at which they were given.

The general pattern was for the parents allocated to the GP clinic to appear to show more discrimination in the consent they gave, slightly less giving consent (as recorded on the computer record) to any part of the triple course than at the other clinics, and only about $80 \%$ giving consent to measles immunisation compared with $97 \%$ and $93 \%$, respectively, in the health centre and child health clinic. Only the child health clinic obtained a high rate of - consent for pertussis immunisation, $90 \%$ compared with $69 \%$ and $69 \%$ in the other two clinics. Once consent had been given, however, the tendency was for the uptake to be higher in the GP clinic, particularly for measles immunisation, and for the median age at which it was given to be lower than in the other two clinics.

The consequences of these findings are illustrated by the graphs in Figures 1 and 2, showing as an example cumulative uptake of the third dose of the primary course (with or without pertussis immunisation) by different months of age in children allocated to the different clinics. Figure 1, where the uptake is calculated as a proportion of those who had consented, shows that the GP clinic consistently obtained higher rates and at younger ages than the other two clinics, the lowest rate being in the health centre. Figure 2, where uptake is calculated out of the total number of children allocated to each clinic, shows that towards the end of the period documented for the cohort, the uptake in the child health clinic had overtaken that in the GP clinic, simply because of the higher proportion of children eligible for immunisations, the parents having given consent. In both cases the uptake figure relates to immunisations given inside and outside the allocated clinic.

We cannot say from these data whether these differences can be attributed to the organisation, or

Table 3 Comparative data on immunisation performance, 1982 births only. Resident at 28 June 1984

\begin{tabular}{|c|c|c|c|}
\hline & \multicolumn{3}{|l|}{ Clinic } \\
\hline & $G P$ & Health centre & Child health \\
\hline No allocated & 121 & 166 & 169 \\
\hline \multicolumn{4}{|l|}{$\begin{array}{l}\% \text { (No) giving consent to: } \\
\text { Diptheria/tetanus with }\end{array}$} \\
\hline or without pertussis & 92 (111) & $98(162)$ & $96(163)$ \\
\hline Pertussis & $69(84)$ & $90(149)$ & 69 (117) \\
\hline Measles & 79 (96) & 97 (161) & 93 (158) \\
\hline \multicolumn{4}{|l|}{$\begin{array}{l}\% \text { Of those consented who } \\
\text { received antigen ( } \% \text { of } \\
\text { those allocated): }\end{array}$} \\
\hline \multicolumn{4}{|l|}{$\begin{array}{l}\text { Diptheria/tetanus with } \\
\text { or without pertussis: }\end{array}$} \\
\hline First dose & $97(89 \cdot 3)$ & $94(92 \cdot 2)$ & $97(93.5)$ \\
\hline Third dose & $85(77 \cdot 7)$ & $68(66 \cdot 3)$ & $82(78 \cdot 7)$ \\
\hline \multicolumn{4}{|l|}{ Pertussis: } \\
\hline Third dose & $85(58.7)$ & $66(59 \cdot 0)$ & $82(56 \cdot 8)$ \\
\hline Measles* & $74(66 \cdot 1)$ & $32(32 \cdot 5)$ & $39(37 \cdot 9)$ \\
\hline \multicolumn{4}{|l|}{$\begin{array}{l}\text { Median age in days } \\
\text { at immunisation: }\end{array}$} \\
\hline $\begin{array}{l}\text { First dose of triple } \\
\text { (or double) }\end{array}$ & 129 & 148 & 133 \\
\hline $\begin{array}{l}\text { Third dose of triple } \\
\text { (or double) }\end{array}$ & 314 & 375 & 351 \\
\hline Measles & 555 & 587 & 581 \\
\hline
\end{tabular}

*The youngest child in the cohort was aged 18 months at the time of the analysis.

'Consent' is taken to be as recorded on the computer. It does not include a small number not recorded as having given consent. but who still bring the child for immunisation.

Table $4 \%$ Of children resident as at 28 June 1984 receiving the third dose of their primary course at the clinic which they were allocated

\begin{tabular}{lrrrr}
\hline & \multicolumn{3}{c}{ Clinic } & \\
\cline { 2 - 4 } & $G P$ & Health centre & Child health \\
\hline No who gave consent & 111 & 162 & 163 \\
$\%$ Immunised at that clinic & 80 & 46 & 70 \\
$\%$ Immunised elsewhere & 5 & 22 & 12 \\
$\%$ Immunised anywhere & 85 & 68 & 82 \\
\hline
\end{tabular}




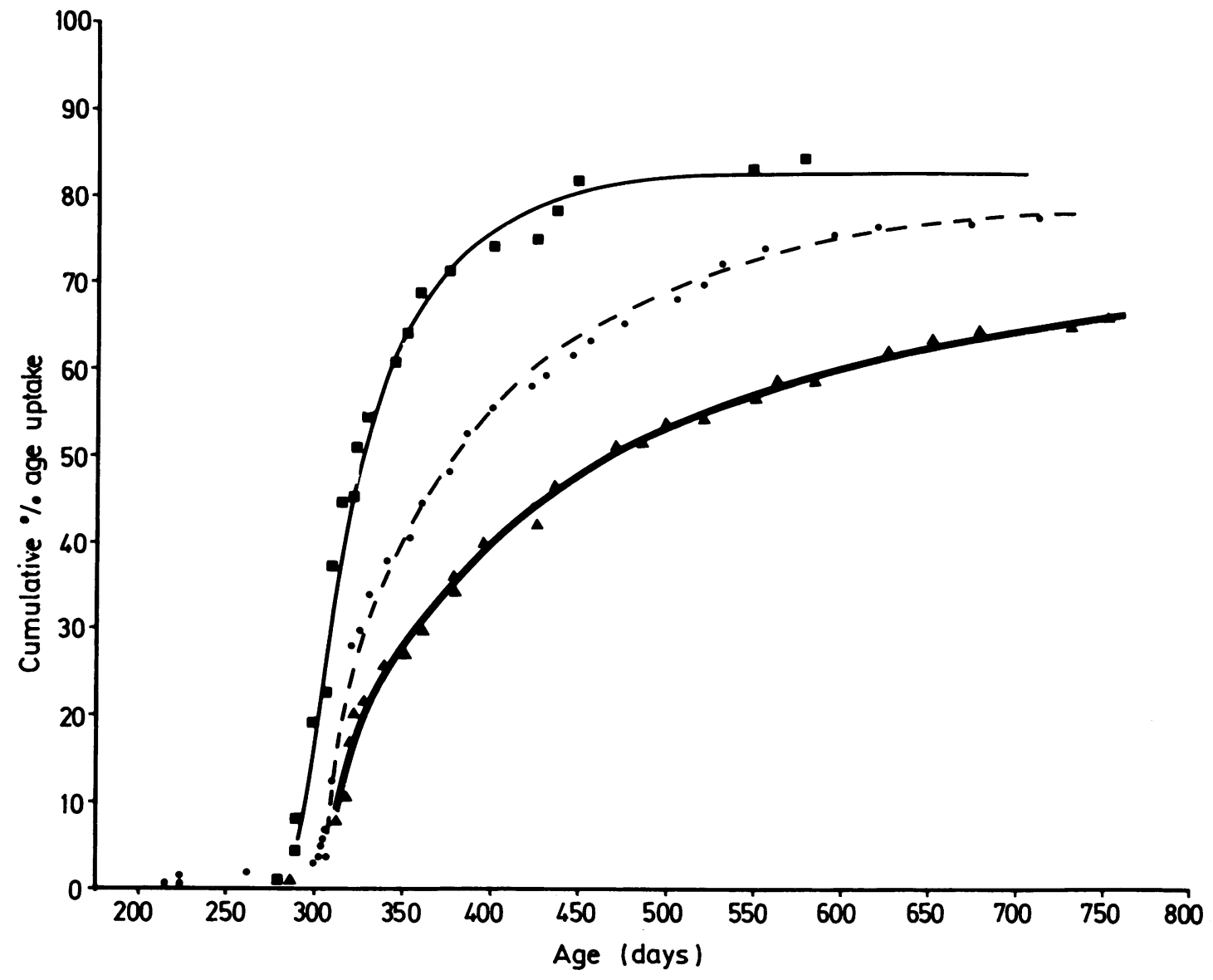

Fig. 1 Cumulative \% uptake of the third dose of the primary course in those with consent by allocated clinic $(\mathbf{\square}=G P$ clinic; $\mathbf{0}$ child health clinic; $\boldsymbol{\Delta}=$ health centre clinic).

1982 Births only resident at 28 June 1984.

other characteristics, of the clinics, or to the contrast between their clients or the high rate of movement, particularly in the health centre clients. This pattern of differences between the clinics was found, however, to be consistent in the five birth cohorts, 1980 to 1984, thus supporting the finding in the 1982 cohort.

Place of immunisation. Parents did not always use the clinic to which they were allocated for immunisations, as shown in the example given in Table 4 for the third dose of the primary course. Of those babies allocated to the health centre, over one fifth received this dose at another clinic, which was often one they had previously attended. As might be expected, this was less true in the GP clinic, where only $5 \%$ of these injections were given elsewhere.
Table 5 Estimated costs: one clinic session for one year

\begin{tabular}{|c|c|c|c|}
\hline & \multicolumn{3}{|l|}{ Clinic } \\
\hline & $G P$ & Health centre & Child health \\
\hline \multicolumn{4}{|l|}{$\begin{array}{l}\text { Average cost of staff per } \\
\text { clinic session for one } \\
\text { year }{ }^{*} \text { : }\end{array}$} \\
\hline Medical & $2.0 \times 1.544$ & $2.0 \times 1.544$ & $1.5 \times 1.544$ \\
\hline Health visitor & $1.5 \times 8(1) 1$ & $3 \cdot 0) \times 8(01$ & $1.5 \times 801$ \\
\hline Clerical & $0.5 \times 640$ & $0.5 \times 640$ & $1.0 \times 640$ \\
\hline Auxiliary & $1.01 \times 640$ & $1.0 \times 640$ & $(0.5 \times 640$ \\
\hline Interpreter & & $2 \cdot 0 \times 6(0)$ & \\
\hline All & 5250 & 7651 & 4478 \\
\hline $\begin{array}{l}\text { Domestic costs (carctaker, } \\
\text { cleatning, rent and rates. } \\
\text { furnishing. elc) }\end{array}$ & 11.38 & 1138 & 885 \\
\hline $\begin{array}{l}\text { Pharmacy ordert } \\
\text { (Antigens, syringes. etc) }\end{array}$ & 225 & 275 & 303 \\
\hline Total cost (f) & 6613 & $y(k 4$ & 5666 \\
\hline
\end{tabular}

No of staff $x$ average salary.

fitimated from actuat orders for 10 months. 


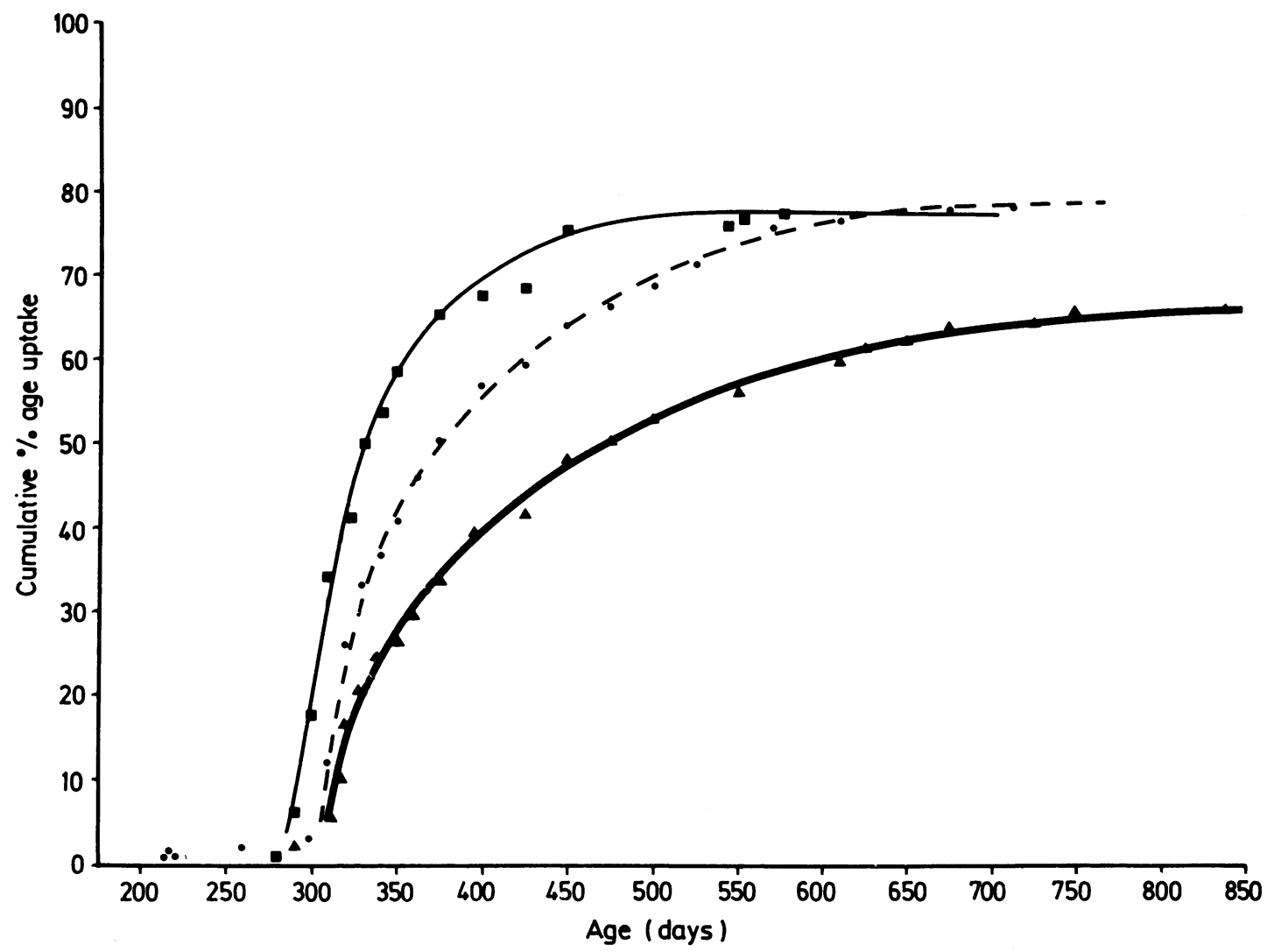

Fig. 2 Cumulative \% uptake of the third dose of the primary course of all children allocated to each clinic regardless of consent state $(\mathbf{\square}=$ GP clinic; $\mathbf{O}=$ child health clinic; $\boldsymbol{\Delta}=$ health centre clinic).

1982 Births only resident at 28 June 1984.

Costs. Table 5 shows that overall the costs for each session in the clinics in the renovated health centre were higher than in the clinic outside. Because of missing data several assumptions have had to be made to estimate these costs; for instance the domestic and pharmacy costs of the GP clinic and health centre could not be separated and we have arbitrarily divided the domestic costs by two and the pharmacy costs in the proportion of total immunisations given. These were derived by a manual search of one year's clinic records for any dose given, excluding polio and BCG.

When the estimated costs were related to the total number of children aged under 5 allocated (Table 6 ), given the assumptions made, the average cost for each session for each allocated child varied from $£ 8.78$ in the GP clinic and $£ 9.07$ in the health centre to only $£ 6.49$ in the child health clinic. The higher cost of the health centre was due to the attendance
Table 6 Average number of immunisations* given to children aged under 5 between April 1983 and March 1984

\begin{tabular}{|c|c|c|c|}
\hline \multirow[t]{2}{*}{ Per session } & \multicolumn{3}{|l|}{ Clinic } \\
\hline & $G P$ & Health centre & Child health \\
\hline $\begin{array}{l}\text { Average No of } \\
\text { immunisations in } \\
\text { one year }\end{array}$ & 248 & 304 & 404 \\
\hline $\begin{array}{l}\text { No of children aged under } \\
5 \text { allocated to clinic } \\
\text { Average No of } \\
\text { immunisations per child } \\
\text { allocated }\end{array}$ & 753 & 999 & 873 \\
\hline
\end{tabular}

${ }^{*}$ Excludes polio and BCG.

of interpreters, and after this had been excluded the average cost fell to $£ 7 \cdot 87$, less than that of the GP clinic.

Table 6 also gives the average number of immunisations given in each clinic for each child 
allocated. It should be remembered that the number of immunisations actually given for each allocated child depends on the proportion for whom consent is obtained and the actual uptake in the latter. It also depends on the place chosen for the immunisation by the parents, whether at or outside the allocated clinic, and will be decreased by attendance of allocated children elsewhere. As the number of immunisations given for each allocated child was least in the health centre (Table 6), and the clinic costs are fixed, this would make the cost for each dose per child particularly high in this clinic.

\section{Discussion}

The aim of the report is to describe ways of developing useful performance indicators relating to childhood immunisation, both to its coverage and its cost. To achieve these we have built further upon recent work relating to ways of presenting the immunisation coverage of different groups of the population by exploiting the Child Health Computer System. ${ }^{34}$ The system can be used to compare the coverage at different ages in different clinics and to relate this to characteristics of the clients.

The findings relating rate of consent to immunisation to compliance in the different clinics are challenging. Although for the first dose of the primary course, with or without pertussis immunisation, compliance-that is, uptake-was fairly high for all the clinics, by the third dose compliance was considerably lower for the health centre. Here the population was largely Bengali, and the results of a previous study suggest their rate of adverse reaction (or perceived adverse reaction) was higher than in the indigenous population (Watson E. Unpublished report).

Further intensive studies are needed of the process of obtaining initial consent for immunisation and the reasons for non-compliance in those who refuse a given course of immunisations outright and in those who fail to take up subsequent doses in the same course.

A question not tackled in this account is the effect on uptake rates if the denominator population is varied, for instance by using the number of births occurring two years before the completion of the primary course rather than the number of children allocated at the time of the third dose. This question will be considered in a separate report currently in preparation.

Table 5 shows that even putting aside payments to GPs for immunisations there may be considerable differences in the costs between one clinic and another. The major difference in this small selected study seemed to be between the costs in the GP and health centre clinics on the renovated site and those in the health authority (child health) clinic. The excess was due both to higher overheads and to increased medical staffing ratios.

Macfarlane has suggested that major savings in cost may be made by using nurses to carry out immunisations. ${ }^{5}$ Using the present estimates it seems that the situation is more complex, as was pointed out by Carne. ${ }^{6}$ As would be expected intuitively, it depends also on the average number of immunisations given in relation to the fixed costs of the clinics.

From this small study it is impossible to draw any general conclusions about differences between GP and health authority child health clinics, but it is hoped this methodology will be used in a larger study designed to answer this question.

The authors acknowledge with gratitude the help of all the staff at the three clinics studied. The work was supported by a grant from the Department of Health and Social Security.

\section{References}

' Macfarlane JA, Pillay U. Who does what and how much in the preschool health services in England. Br Med J 1984;289:851-2.

2 Walker CHM. Child health records and computing. Br Med J 1982;285:1671.

${ }^{3}$ Scrivens E. Management information in the National Health Service: the use of the child health computer system. Community Med 1984:6:299-305.

${ }^{4}$ Baker MR, Bandaranayake R, Schweiger MS. Differences in rate of uptake of immunisation among ethnic groups. $\mathrm{Br}$ Med $\mathrm{J}$ 1984;288:1075-8.

5 Macfarlane JA. Whose job is it to give immunisation. Maternal and Child Health 1984;9:302-5.

' Carne S. A reply to Macfarlane. Maternal and Child Health 1984:9:305-6.

Correspondence to Professor E D Alberman, Department of Clinical Epidemiology, The London Hospital, London E1 1BB.

Received 7 November 1985 